\title{
RELAÇÕES ENTRE SER HUMANO E NATUREZA: UMA REFLEXÃO SOBRE A SOCIEDADE CONTEMPORÂNEA
}

Teresinha Maria Gonçalves

José Ivo Follmann

\section{RESUMO}

Este artigo se constitui como um aporte teórico na perspectiva de uma reflexão sobre os valores que orientam as relaçõesdo ser humano entre si e deste com anatureza. Apresenta uma discussão sobre a produção da subjetividade na sociedade contemporâneano contexto onde a qualidade de vida recoloca os valores associadosà vida e à dignidade. Questiona o atual modelo desenvolvimento que exacerba a degradação socioambiental, exaure a natureza e aumenta as desigualdades sociais. Urge, neste contexto, investir na mudança de valores e atitudes socioambientais, pois que a degradação do ambiente reflete, em última instância, a própria degradação dos seres humanos e da humanidade, em sua incapacidade de reconhecimento de sua própria dignidade e do valor da vida.

Criar Educação, Criciúma, v. 6, no2, julho/novembro 2017.- PPGE - UNESC 


\section{RELAÇÕES ENTRE SER HUMANO E NATUREZA: UMA REFLEXÃO}

\section{SOBRE A SOCIEDADE CONTEMPORÂNEA}

\section{Teresinha Maria Gonçalves}

\section{José Ivo Follmann}

\section{RESUMO}

Este artigo se constitui como um aporte teórico na perspectiva de uma reflexão sobre os valores que orientam as relaçõesdo ser humano entre si e deste com anatureza. Apresenta uma discussão sobre a produção da subjetividade na sociedade contemporâneano contexto onde a qualidade de vida recoloca os valores associadosà vida e à dignidade. Questiona o atual modelo desenvolvimento que exacerba a degradação socioambiental, exaure a natureza e aumenta as desigualdades sociais. Urge, neste contexto, investir na mudança de valores e atitudes socioambientais, pois que a degradação do ambiente reflete, em última instância, a própria degradação dos seres humanos e da humanidade, em sua incapacidade de reconhecimento de sua própria dignidade e do valor da vida.

Palavras chaves:valores socioambientais, produção da subjetividade, sociedade, natureza, qualidade de vida.

RELATIONS BETWEEN HUMAN BEING AND NATURE: A REFLECTION ON A CONTEMPORARY SOCIETY.

\section{ABSTRACT}

Criar Educação, Criciúma, v. 6, no2, julho/novembro 2017.- PPGE - UNESC 
aves:valores socioambientais, produção da subjetividade, sociedade, natureza, qualidade de vida.

\title{
RELATIONS BETWEEN HUMAN BEING AND NATURE: A REFLECTION
}

\section{ON A CONTEMPORARY SOCIETY.}

\begin{abstract}
This article constitutes a theoretical contribution in the perspective of a reflection on the values that guide the relations of the human being among themselves and of this with the nature. It presents a discussion about the production of subjectivity in contemporary society in the context where the quality of life replaces the values associated with life and dignity. It questions the current development model that exacerbates socioenvironmental degradation, exhausts nature and increases social inequalities. In this context, it is urgent to invest in the change of socio-environmental values and attitudes, since the degradation of the environment ultimately reflects the degradation of human beings and humanity, their inability to recognize their own dignity and the value of life . Keywords: socio-environmental values, production of subjectivity, society, nature, quality of life.
\end{abstract}

\section{INTRODUÇÃO}

O ponto de partida, neste artigo, é a formação de valores na sociedade contemporânea e os seus níveis de degradação e desequilíbrios, buscando, de uma forma

Criar Educação, Criciúma, v. 6, no2, julho/novembro 2017.- PPGE - UNESC 


\section{CRIAR EDUCAÇÃO}

Revista do Programa de Pós-Graduação em Educação - UNESC

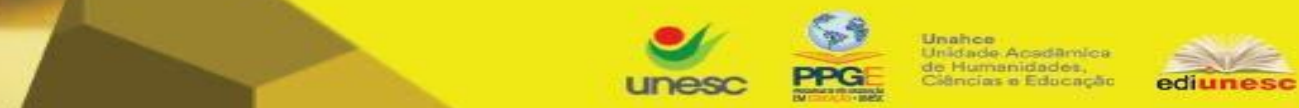

bastante sóbria, pontuar, na sequência, alguns aspectos considerados fundamentais na discussão dos valores nas relações que os seres humanos estabelecem com a natureza.

Passando pelas noções de qualidade de vida, pelas consequências da chamada pós-modernidade e dos apelos da sustentabilidade humana, do bem-estar, o artigo culmina sinalizando rumos entendidos como necessários em termos de valores dos seres humanos em suas relações de reconhecimento e cuidados para com a vida em todos os sentidos epara com a natureza.

\section{A FORMAÇÃO DE VALORES NA SOCIEDADE CONTEMPORÂNEA}

O sujeito se funda na coletividade, ou seja, só é possível se constituir sujeito, pelooutro. O sujeito é individual no sentido de ser um ser singular, único, com sua história, sua personalidade, seus desejos e sua visão de mundo. A humanidade impressa no sujeito é dada pela coletividade, pelo ato de relacionar-se com seus semelhantes. Nessa perspectiva são construídos os valores humanos que se agregam à vida no sentido de torná-la possível de forma pacífica, saudável, criativa e, portanto, sustentável.

A síntese de tudo, a rigor, está na sustentabilidade. Entretanto, o conceito de sustentabilidade vem sendo profundamente contaminado pelo conceito desustentabilidade econômica. Trata-se de um viés de perversão introduzido pelo próprio modelo de desenvolvimento que impera em nossas sociedades.

A reflexão que aqui é proposta é conduzida por um esforço para construir o conceito de sustentabilidade de uma forma que rompa com este viés, tomando como suporte para tal, os próprios avanços da sociedade humana neste sentido. O Programa

Criar Educação, Criciúma, v. 6, no2, julho/novembro 2017.- PPGE - UNESC 
das Nações Unidas para o Desenvolvimento, por exemplo, aborda o conceito do

Desenvolvimento Humano Sustentável mencionando as dimensões da erradicação da pobreza, a promoção da equidade e a inclusão sociais, da igualdade de gênero e raça, da sustentabilidade ambiental, da participação política dos direitos humanos.

Trata-se de princípios morais e sociais ligados à teoria do Estado de Direito e da cidadania $^{1}$. Isto, segundo a autora supõe subjetividade integrada, conceito emprestado de $\mathrm{Pol}^{2}$, amorosidade, criatividade e solidariedade. É fundamental que se considere, em primeiro plano, a noção de subjetividade integrada, como trabalhao autor ${ }^{2}$. A subjetividade integrada é entendida como o nosso mundo interno que é constituído, de forma integrada, de várias dimensões: cognitiva, afetiva, interativa, simbólica e estética. Quando, nesse campo da subjetividade somente se desenvolve, preponderantemente o cognitivo, em detrimento das outras dimensões, têm-se uma subjetividade fragmentada e, portanto, inibidora de um crescimento saudável, criativo do sujeito. A autora ${ }^{1}$ destaca ainda a necessidade a importância da emergência de sujeitos amorosos, criativos e solidários. É rigorosamente decorrência de uma autêntica subjetividade integrada, cultivada em uma perspectiva crítica e de superação dos próprios círculos egocêntricos.

Isso aponta para uma avaliação do sentido da existência humana, da qualidade doconsumo, da qualidade do trabalho e numa expectativa de vida, de paz e de felicidade que vá além dos problemas de emprego, de salário e de distribuição equitativa da renda. Colocar em questão a qualidade de vida envolve também de forma radical as relações interpessoais, que muitas vezes estão marcadas pela indiferença e pelo descompromisso com o outro.Quandoo conceito de competitividade substitui o de colaboração e o de egoísmoode solidariedade, instala-se na sociedade um estranhamento, um mal estar que 
CRIAR EDUCAÇÃO

Revista do Programa de Pós-Graduação em Educação - UNESC

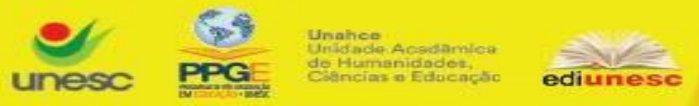

é sentido de maneiras diferentes, pelos discriminadores e pelos discriminados. Os emblemáticos muros que separam a Cisjorânia de Israel, Espanha e Marrocos Estados Unidos e México e, mais perto de nós aqui na AméricaLatina,o muro que separa ricos e pobres na cidade de Lima no Perú, com $10 \mathrm{~km}$ de extensão e mais de 3 metros de altura coloca em cheque os conceitos de sustentabilidade e de desenvolvimento que tanto se discute no âmbito das ciências ambientais.

Onde estão, no nosso cotidiano, os valores ligados à vida, ao bem comum, à liberdade, à ética essenciais para aconstrução da subjetividade e ao projeto de vida?O nível de degradação subjetiva pode chegar ao ponto em que os parâmetros do serfeliz ou do sofrer não mais estão separados e discriminados para poderem ser vividosdiferentemente pelos indivíduos confundidos pela banalização da dor e do sofrimento.

Em nossas pesquisas realizadas no contexto do Programa de Pós-Graduaçãoem Ciências Ambientais da UNESC (Universidade do Extremo Sul Catarinense), através do Laboratório de Meio Ambiente, Desenvolvimento Urbano e Psicologia Ambiental nos deparamos muitas vezes, com a solidão de jovens de todas as classes sociais, com o seu vazio existencial, que procura ser preenchido por tempos incontáveis frente às telinhas dos celulares.A massificação do consumo, a banalização da violência (dentro e fora do ambientefamiliar), a concentração da riqueza e a degradação ambiental contribuem grandemente para o empobrecimento (material e emocional), acentuando sempre mais as limitações do Estado em prover os serviços básicos a uma população crescente, marginalizada pelos circuitos da produção e do consumo e sem efetivos canais de participação na organização da vida em sociedade.

Criar Educação, Criciúma, v. 6, no2, julho/novembro 2017.-PPGE - UNESC 
Essa situação tem gerado disfuncionalidade ambiental, social e moral, pois ao mesmo tempo em que o mercado se amplia, gera a uniformização dos bens de consumo que são, muitos deles, produzidos em condições ecológicas e culturais nas quais a canalização de importantes recursos econômicos é priorizada e do, isto é, tudo para a produção e muito pouco para as políticas sociais.

A dimensão cultural é determinante para a noção de qualidade de vida, pois sugereque o processo de produção e de satisfação das necessidades ultrapasse as necessidades materiais. Ela supera a divisão simplista entre a necessidade objetiva e a de caráter subjetivo, assim como também a dicotomia entre fatores biológicos e psicológicos, incorporando a determinação cultural das necessidades.

$\mathrm{O}$ autor ${ }^{3}$ diz que lidar com responsabilidades e compromissos éticos demanda a construção de sistemas discursivos, que contenham uma reflexão crítica e que alimentem o nosso imaginário e nos deem novas formas de conhecimento diferentes daquelas quesão muitas vezes descritascomo sendo marcadamente do empreendedor capitalista.

Nesse cenário ${ }^{3}$ coloca que há um antropocentrismo declarado o que ele chama de "comunitarismo" com uma dicotomia, ao mesmo tempo,uma "complementação" entre local-globale aceito pela sociedade capitalista neoliberal onde se coloca a natureza a serviço do homem de uma forma normalizada.

Como "contra-corrente", concepções ecocentristas e biocentristas evidenciam e denunciam que existem concepções diferentes e radicalmente alternativas, como são as dos povos indígenas e dos povos tradicionais. Harvey assim se expressa:

Criar Educação, Criciúma, v. 6, no2, julho/novembro 2017.-PPGE - UNESC 
As concepções inseridas cultural e histórico-geograficamenteem particular dos povos indígenas não se coadunam bem com alegações e princípios universais, com frequência apresentados por cientistas ${ }^{4}$.

Existem aspectos a considerar que ultrapassam as racionalidades científicas habituais. Há urgência de uma nova epistemologia que aponte para novos paradigmas.O autor ${ }^{5}$ propõe uma nova epistemologia ambiental para se compreender os problemas socioambientais da América Latina.

\section{A NOÇÃO DE QUALIDADE DE VIDA}

A noção de qualidade de vida traz, em suas análises, as noções de bem-estar, nívelde ingresso, condições existenciais e estilos de vida, que se entrecruzam com processoseconômicos e ideológicos na definição de demandas simbólicas e materiais, na imposição de modelos de satisfação com os apelos da propaganda que manipula odesejo das pessoas ${ }^{6}$.

Os valores culturais determinam a estruturação das necessidades e da demanda social,assim como dos meios para satisfazê-las. Existem diferentes vias para estabelecer uma qualidade de vida, que vá desde as formas menos materiais até as mais refinadas da cultura.O que é mais importante para uma pessoa num determinado momento? Quem possuicasa, carro, emprego, seguro-saúde e escola garantida para os filhos tem 
CRIAR EDUCAÇÃO

Revista do Programa de Pós-Graduação em Educação - UNESC

expectativa diferente em relação à qualidade de vida de quem moraem comunidades pobres e vulneráveis?

A noção de qualidade de vida implica abertura dos desejos e das aspirações para além da satisfação das necessidades básicas. Requer desejo de cidadania, participação garantida na gestão das políticas públicas, solidariedade e acesso aos direitos e bens comuns, de esperança e felicidade.

Através desta noção assim colocada, os valores associados com as restrições de consumo,estímulo e crescimento econômico, satisfação das necessidades individuais diante dasexigências para a reprodução social, são revistos. São questionados, também, os benefícios alcançados pelas economiasde escala, de aglomeração e a racionalidade do consumo que tende a maximizar o benefíciopresente em prejuízo do futuro.

Entretanto, muitos desses esforços não conseguem superar a racionalidade produtivadominante. Esta racionalidade não é questionada na perspectiva social e moral. Porexemplo, até chega a ser reconhecida a importância do acesso da população, no contexto do trabalho produtivo, a certas"amenidades" recreativas e à participação nas tomadas de decisão. No entanto, nãose colocam as necessidades como as de autogestão dos recursos, do rompimento dos atuaispadrões de consumo e as implicações macromecânicas, que gerariam maior auto-suficiência dascomunidades fundadas em consumo diversificado. Isso levaria à redefinição das necessidadesbásicas, como nutrição, saúde, moradia, vestuário, educação, emprego e participação.

Uma questão importante para análise da qualidade de vida é a percepção que aspessoas têm das suas condições de existência. Isso passa pela compreensão de que o mundointerno do sujeito é constituído pela internalização do mundo externo ${ }^{7}$.

Criar Educação, Criciúma, v. 6, no2, julho/novembro 2017.- PPGE - UNESC 
CRIAR EDUCAÇÃO

Revista do Programa de Pós-Graduação em Educação - UNESC

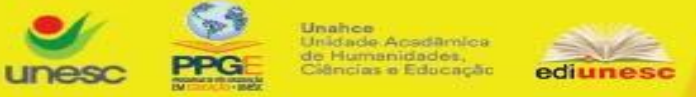

A forma deinternalizar depende de cada indivíduo, e as comunidades urbanas e rurais podem perceber demodo diferente, problemas e situações. Cada indivíduo, conforme a cultura, internaliza signos destatus e de noções de modernidade, vistos como melhoria de sua qualidade de vida, semperceber as disfunções e as nãoadaptações que podem ocorrer no seu estado de saúde e nobem-estar geral.

Nesse sentido, a percepção das condições de existência gera processos deadaptação às situações impostas ou a mobilização social em protestos, incorporandose aoindivíduo em suas lutas demandadas por novas formas de satisfação de necessidades, fora dasnormas estabelecidas pelos benefícios da economia de mercado.

\section{OS FILHOS DA PÓS-MODERNIDADE}

O que podemos perceber é que a configuração deste novo sujeito mostra a face deuma subjetividade cheia de vazios, onde a insegurança, o medo de errar, a falta de amor próprio,as dúvidas, a falta de motivações e esperança configuram uma subjetividade desestruturada ${ }^{8}$.

Trata-se de estado de vida em que qualquer pequena frustração ou desencontro pode desencadear processos limites e radicais. A falta de segurança e referências gera um navegar em uma obscuridade que pode trazer sobressaltos assustadores e incontroláveis.

Então, mostram-se os sintomas patológicos da nova estrutura do lar, e, por conseguinte dasociedade, onde não se propicia mais o espaço para a vida simbólica, 
emoções, onde não sedemonstra mais o amor, mas vive-se em função do ter e do que se percebe como concreto da vida.

Segundo o autor ${ }^{8}$ é com a prevalência desta estrutura familiar que nossos jovens internalizam valoresdeturpados em que o ter é mais importante do que o ser. Deparamonosnos corredores dasuniversidades, nas ruas das cidades, nas festas de fim de semana, com jovens que são apersonificação real da figura de "deus-bebê", que a autora refere em seus textos, ao descrever osujeito se comportando na sociedade como criança ou como um narciso autocentrado expresso numegoísmo extremado, resultando em atitudes desastrosas que nada acrescentam para si e para asociedade. E podemos ver isso de maneira muito real por meio do consumismo exacerbado, vistoque são presas fáceis da sedução de propagandas bem elaboradas, pensadas para atingir suaemoção, sua vaidade e sua insegurança.

Pensando em si mesmo, em "aparecer" para seusamigos e "sair-se bem na foto", para mostrar-se nas comunidades cybers, o jovem contemporâneosai na busca de si mesmo, tentando achar-se em vários e múltiplos lugares.Será que ainda podemos falar de afetividade, da força do afeto? Falar de amor, desolidariedade, de harmonia, de alegria? O que acontece com os tempos modernos ou pós-modernos?O amador da vida faz do mundo a sua família? Que família? Parece que na pós-modernidadese evoca um tempo que não mais existe. Mas a necessidade de não nos perdermosnos joga para a crença de que esse tempo ainda existe. Trata-se de um tempo de outro espaço, ou em outra dimensão humana onde os valores forjados na cultura da ética e da solidariedade prevaleçam.

Criar Educação, Criciúma, v. 6, no2, julho/novembro 2017.-PPGE - UNESC 
Entretanto, esse espaço evocado da vida sociocultural não coincide com o tempo

presenteno qual ainda evocamos uma família bem estruturada para que, aí, o jovem cresça emocionalmentesaudável. Estamos sendo ingenuamente românticos? O que vemos é um eu insaciável do "nãoeu" que, no dizer do autor", a cada instante revela em imagens vivas a fragilidade davida sempre instável e fugidia. O "não eu" e o não lugar fazem parte da novidade matizada da pós-modernidade“Os ambientes e experiências modernos cruzam todas as fronteiras da geografia eda etnicidade, da classe e da nacionalidade" ${ }^{\prime 10}$. Os jovens de classe médiade Criciúma, por exemplo, divertem-se à noite fazendo um tour pelos lugares de diversão e não ficam emnenhum deles. É o que foi amplamente demonstrado em pesquisa do GIPMAUR ${ }^{11}$.

Os jovens se veem como perdidos em alto mar numa canoa que orabalança, e que ora é arremessada contra os rochedos da vida moderna comtodos os seus sustos, seus medos e sua insegurança.

Inseguros e desencantados! Este parece sero retrato do jovem pós-moderno que procura no turbilhão das páginas dainternet ou na multidão que enche as ruas e avenidas das grandes metrópoles, as respostas que nunca encontra.O que dizer de nossas crianças e nossos jovens que habitam as periferias de nossascidades hoje? $\mathrm{O}$ problema das periferias urbanas na visão de Paugam $^{12}$ nãopode ser explicado só pelas formas de segregação espacial e a desigualdade face à habitação. Omais cruel é a degradação das relações sociais no seio das cidades deserdadas e as dificuldadescrescentes da população diante do sentimento de solidão, de desesperança, de vazio daexistência.

Se hoje o debate não repousa mais enfaticamente sobre as desigualdades sociais, nãoé porque elas tenham desaparecido, mas são, segundo o autor citado, "renovadas sob

Criar Educação, Criciúma, v. 6, no2, julho/novembro 2017.-PPGE - UNESC 


\section{CRIAR EDUCAÇÃO}

Revista do Programa de Pós-Graduação em Educação - UNESC

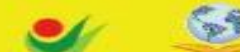

unesc PPG:

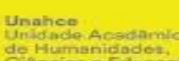

diversasformas e não são mais suficientes, por elas mesmas, para explicar os fenômenos

de ruptura dacrise identitária que caracteriza o processo de exclusão" ${ }^{\text {"12 }}$. A crise da modernidade ou da pós-modernidade, como diz o autor ${ }^{9}$, entre outrascoisas se caracteriza pelo esfacelamento do sujeito.

A pobreza não é um fenômeno novo, mas agora ela é fabricada, como consequência da modernização. $O$ estatuto individual de que falao autor ${ }^{8}$ chegou também até eles. O sentimento de frustração em querer coisasmateriais, status e não poder, remete-os a uma culpa por sentirem-se impotentes e derrotados nacompetição com os demais.

\section{VALORES NA COOPERAÇÃO E SUSTENTABILIDADE DA VIDA}

Segundo os autores ${ }^{13}$ não se trata, evidentemente, de um desejo de mistificação e, muito menos, de umabusca do retorno da magia. Não se trata de um retorno ao animismo. Segundo os autores, a"antiga aliança" animista está morta e bem morta. O apelo assume posição pela derrubada dasfronteiras artificiais existentes no processo de conhecimento humano, na busca de umareaproximação do ser humano com a natureza, pois o nosso mundo também não é o da "aliançamoderna".Hoje presenciamos uma "nova aliança".

Chegou o tempo de novas alianças, desdesempre firmadas, durante muito tempo ignoradas, entre a história dos homens, de suassociedades, de seus saberes, e a aventura exploradora da natureza ${ }^{13}$.

Criar Educação, Criciúma, v. 6, no2, julho/novembro 2017.- PPGE - UNESC 


\section{CRIAR EDUCAÇÃO}

Revista do Programa de Pós-Graduação em Educação - UNESC

A ciência moderna, de certa forma, se constituiu contra a natureza, pois lhe negava acomplexidade, pretendendo reduzi-la a leis acessíveis ${ }^{13}$. A ciência não é só manipulação da natureza, mas é também e, sobretudo, esforço paracompreendê-la. "A natureza recusa exprimir-se na linguagem que as regrasparadigmáticas supõem, e a crise (...) explode com tanto mais força, quanto era cega aconfiança"13.

O relatório da Comissão Gulbenkian para a Reestruturação das Ciências Sociais, em1996 ${ }^{14}$ comenta:

Se isto põe um problema grande aos estudiosos das ciências naturais, aindamaior é aquele que coloca aos cientistas sociais. Transpor o reencantamento do mundo para umaprática razoável e eficaz não será fácil. Mas parece-nos ser uma tarefa urgente para os cientistassociais ${ }^{14}$.

A discussão do conceito de Desenvolvimento Humano e Sustentável certamente devepassar por dentro dessas mesmas preocupações apontadas por Ilya Prigogine e pela ComissãoGulbenkian, no quadro de estabelecer uma reconciliação entre a ciência, a humanidade e a vidanatural (em todas as suas formas e expressões). Necessitamos de um sério processo de reeducaçãopara re-habilitar o paradigma da harmonia, soterrado sob o entulho da desarmonia e daviolência

Um passo necessário é a transdisciplinaridade que, ao estabelecer um novo diálogoentre saberes disciplinados e "não-disciplinados", facilita o ressurgimento de perspectivas epercepções esquecidas pela racionalidade moderna, mas radicalmente

Criar Educação, Criciúma, v. 6, no2, julho/novembro 2017.- PPGE - UNESC 
moderna"Com a intensificação do processo de globalização mudanças ambientais globais,assiste-se, no presente, à exacerbação da degradação ambiental do planeta. Como já foi sinalizado anteriormente, as cidades, pontose áreas de flagrante destaque neste cenário, registram os mais graves problemas relativos àdegradação do ambiente e da sociedade.

Estudos diferentes, em distintos locais do planeta, têmindicado a necessidade de mudanças urgentes do padrão de desenvolvimento ocidental comoforma de reduzir a degradação e promover a qualidade e as condições de vida da população.

Urge, neste contexto, investir na mudança de valores e atitudes da sociedade, pois que adegradação do ambiente reflete, em última instância, a própria degradação do ser humano e da suaforma de viver em sociedade. Recuperar a degradação dos elementos da natureza resultará, de forma direta, narecomposição das condições ambientais necessárias ao desenvolvimento humano e dasociedade, todavia faz-se mister apostar, primeiramente, no resgate dos valores que alicerçam arelação entre os próprios seres humanos, e entre estes e a natureza.

O sucesso da luta ambientalista, buscando a preservação e a conservação ambiental,somente logrará sucesso se investirmos na busca de ajudar a população tomar consciência, por meio do pensamento crítico, destacando oimportante papel dos sujeitos na promoção de uma vida que seja rica em valores humanos, enão embasada no consumismo que marca a sociedade ocidental. Aposta, assim, nacompreensão de que é necessário promover um deslocamento da busca de satisfação humanana materialidade da existência, para uma realização plena nas relações que sustentam a vida noplaneta. 
Ainda aliadas à idéia de identidade estão as noções de "tempo" e "espaço".

Segundoo autor ${ }^{10}$, os indivíduos são movidos por seus projetos que requerem tempo emovimento no espaço. Dessa forma,

(...)as biografias individuais podem ser tomadas como "trilhasda vida no tempo e espaço, começando com rotinas cotidianas de movimento (da casa para afábrica, as lojas, a escola, e de volta para casa) e estendendo-se a movimentos migratórios quealcançam a duração de uma vida $[\ldots]^{10}$

A identidade é um processo histórico-cultural. Aliás, sociologicamente torna-se mais apropriado centrarmos a nossa atenção dos processos de identidade, mais do que nas identidades propriamente, pois estas sempre estão em processo. Segundo o autor:

É na maneira com queum indivíduo ou um grupo (uma coletividade) estabelece a relação entre seu futuro e seupassado ou, ainda, entre seus projetos e sua trajetória, que temos, de forma particular, asindicações principais para desvendar qual é a sua identidade ${ }^{15}$

Assim, aidentidade inclui o passado e o presente, o vivido e o que está por vir, o que já foi conquistado e oalmejado.

As práticas espaciais e temporais de toda a sociedade são abundantes em sutilezas e em complexidades. Como elas estão estreitamente implicadas emprocessos 


\section{CRIAR EDUCAÇÃO}

Revista do Programa de Pós-Graduação em Educação - UNESC

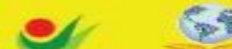

unesc

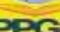

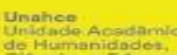
는 ediuneso

de reprodução e transformação das relações sociais, é precisoencontrar alguma maneira de descrevê-las e de fazer uma generalização sobreseu uso.

A história de mudança social é em parte apreendida pela história dasconcepções de espaço e de tempo, bem como dos usos ideológicos que podemser dados a essas concepções. Além disso, todo projeto de transformação dasociedade deve aprender a complexa estrutura da transformação dasconcepções e práticas espaciais e temporais ${ }^{10}$

Os seres humanos se movimentam em uma permanente e complexa costura das dimensões do espaço e do tempo. As degradações espaço-temporais de toda ordem tornam difícil a sua recomposição humana enquanto portadores de vida e de futuro. Somente através de valores como a amorosidade, a criatividade e a solidariedade abrirse-ão as portas desta nova fecundidade.

Talvez tenhamos que acrescer que amorosidade, criatividade e solidariedade só têm condições de vingar efetivamente no chão fértil do reconhecimento. Sem sentir-se profundamente reconhecido como sujeito, o ser humano tende a definhar e a tornar-se estéril em sua amorosidade, criatividade e solidariedade. Ou, pelo lado afirmativo: o reconhecimento é o maior combustível da vida amorosa, criativa e solidária. $\mathrm{O}$ futuro da humanidade reside no cultivo do reconhecimento humano.

\section{SOBRE VALORES HUMANOS}

Criar Educação, Criciúma, v. 6, no2, julho/novembro 2017.-PPGE - UNESC 


\section{CRIAR EDUCAÇÃO \\ Revista do Programa de Pós-Graduação em Educação - UNESC}

As Ciências Humanas nos proporcionam diferentes aproximações. Para a antropologia, para iniciar, cada sociedade e inclusive cada grupo e categoria socioculturaldesenvolve seu sistema de valores, que é aprendido durante o processo de socialização.

Em termos sociológicos, ressalta-se a importância das pessoas, grupos, povos e sociedades tenderem a diferenciar-seentre si, não só pelos valores que professam, mas pelos modos como estes são organizados ehierarquizados em seu respectivo sistema.

Já em nível de abordagem jurídica e política, alguns valores sãoreconhecidos como mais absolutos, universais, globais e "eternos"do que outros, de caráter maisrelativo, particular, local e temporal.

Por fim a chave que a história nos propõe, é que embora os valores se caracterizem pela sua relativaestabilidade, são passíveis de alterações e estão implicados com o contexto sociocultural vigente.

De pouco nos ajudam as ciências, se não nos deixarmos envolver por um profundo sentimento de compromisso frente ao contexto de degradação, desagregação e desequilíbrios vivenciados pela humanidade no momento presente.

Neste contex to que a humanidade vive, não basta, também, trazer à tona o apelo aos valores básicos que estão inscritos nos Direitos Humanos, como o direito à vida, o direito à saúde, à educação, à moradia, ou, mais profundamente, o direito à felicidade, como uma espécie de "tábuas da lei" escritas em um momento de lucidez da humanidade.

Criar Educação, Criciúma, v. 6, no2, julho/novembro 2017.- PPGE - UNESC 


\section{CRIAR EDUCAÇÃO}

Revista do Programa de Pós-Graduação em Educação - UNESC

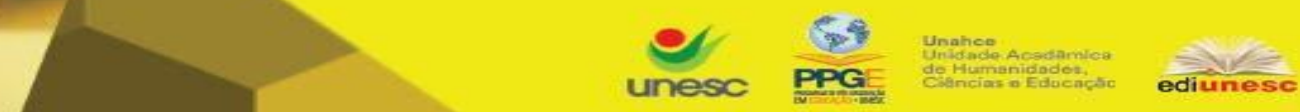

É necessário que o objeto da degradação seja reconhecido em sua dignidade. A

vida em sua diversidade de expressões está sendo degradada. O ser humano está sendo degradado. As relações entre os seres humanos estão sendo degradadas. Aliás, o próprio termo "degradação" é revestido de extremo vigor, quando tomamos consciência de quem é odegradado e, mais radicalmente, quando tomamos consciência de quem é o degradante.

O contrário de ser degradado é ser reconhecido. Quem reconhece a importância de cada ser vivo, cuida do mesmo e busca sempre criar um clima favorável para que ele possa ser, desabrochar, afirmar-se, viver e espalhar vida.

Quando nos perguntamos, hoje, sobre quais são os valores que agregam vida? Quando nos damos conta que a desagregação e a degradação da biosfera vêmacompanhadas da própria desagregação e degradação humanas, só temos uma resposta certeira: a subjetividade integrada da qual nos fala os autores ${ }^{8,2}$ acompanhada de amorosidade, criatividade e solidariedade. Tudo isto sendo cultivado no terreno fértil do reconhecimento. Quando isto não se realiza, o desequilíbrio psicossocial se instaura, decorrendo de processos de violências incontroláveis vividas pelos seres humanos, consigo mesmos, com os outros e em sua relação com a própria natureza.

Observa-se que ao longo da história os desequilíbrios psicossociais, relacionados com desagregações e degradações humanas e sociais, ocupam umaparte importante da vida das pessoas, das famílias, das comunidades, das cidades e dos povos. Isto muitas vezes, e, talvez, em sempre maior frequência, vem acompanhado pelos desequilíbrios, desagregações e degradações da natureza.

Criar Educação, Criciúma, v. 6, no2, julho/novembro 2017.- PPGE - UNESC 


\section{CRIAR EDUCAÇÃO}

Revista do Programa de Pós-Graduação em Educação - UNESC

Como alcançar o bem-viver, a felicidade, a satisfação e sustentabilidade

humanas em um contexto de sempre mais acelerado caminho que aponta para o contrário? Concluímos esta reflexão, com a afirmação daquilo que é o elementar básico: o ser humano e o seu poder transformador. Nada está perdido. Tudo está nas mãos do ser humano. Na medida em que se multiplicaram os gestos criativos de homem e mulher no sentido do amor, do cuidado, do bem querer, da afirmação da vida e da excelência criadora do trabalho humano, mais sementes de reconhecimento estarão sendo semeadas no chão fértil da humanidade.

\section{REFERÊNCIAS}

1. Gonçalves TM. Sobre os conceitos de Desenvolvimento Sustentável e Ecodesenvolvimento. Unesc: Texto produzido para o grupo de trabalho Meio Ambiente e Valores Humanos, Criciúma; 2009.

2. Pol E. La apropriacióndelEspácio. In: Iñguez,L, Pol.E. MonografiesPsicoso-socioambientales. Barcelona:Universitat de Barcelona; 1996.

3. Harvey D.17 Contradiçôes e o fim do Capitalismo. São Paulo: Boitempo Editorial; 2016.

4. Harvey D. Espaços de Esperança. São Paulo: edições Loyola; 2004.

5. Leff., E.Racionalidad ambiental:lareapropiación social de la naturaliza. Buenos Aires: SigloVientiuno Editores; 2004.

6. Galloping $\mathrm{G}$ Calidad de vida y necessidades humanas, sistemas ambientalesvenezoelanos.Caracas: Marnr; 1982.

Criar Educação, Criciúma, v. 6, no2, julho/novembro 2017.-PPGE - UNESC 
7. Rivière HP. O processo grupal. São Paulo: Martins Fontes; 1983.

8. Damergian S. A construção da subjetividade na Metrópole Paulistana: Desafios da contemporaneidade. São Paulo: Educ; 2001.

9. Giddens A. As Consequências da Modernidade.São Paulo: UNESP; 1991.

10. Harvey D. Condição Pós-Moderna. São Paulo: Loyola; 1998.

11. Gipmaur Grupo Interdisciplinar e Interinstitucional de Estudos e Pesquisa sobre Meio Ambiente e Espaço Urbano-Universidade do Extremo Sul Catarinense-UNESC. Os postos de Gasolina transformados em point pelos jovens de Criciúma-SC. Relatório de Pesquisa; 2012.

12. Demo P. Charme da exclusão social. Campinas: Autores Associados; 1998.

13. Prigogine I, Stengers I. A nova aliança:metamorfose da ciência. Brasília: Edtora $\mathrm{UNB} ; 1984$.

14. Wallerstein I. Para abrir as Ciências Sociais. São Paulo: Cortez; 1996.

15. Follmann JI. Identidade como conceito sociológico. Cien. Soc. Unisinos 2001; 37(158):43-66.

Criar Educação, Criciúma, v. 6, no2, julho/novembro 2017.- PPGE - UNESC 